\title{
Cinnamon-induced Oral Mucosal Contact Reaction
}

Dpen Access

\author{
Ana P. M. Vivas and Dante A. Migliari* \\ Department of Stomatology, School of Dentistry, University of São Paulo, São Paulo, Brazil
}

\begin{abstract}
Contact stomatitis associated with consumption of cinnamon flavoring agents is a relatively uncommon disorder. Of relevance, both clinical features and the histopathologic findings of this condition are nonspecific, and, more importantly, may resemble some other inflammatory oral mucosa disorders, eventually making diagnosis difficult. Usually a patient exhibits a combination of white and erythematous patches of abrupt onset, accompanied by a burning sensation. To shed some light on this subject, a case of a 64-year-old woman with hypersensitivity contact reaction on the oral mucosa due to cinnamon mints is presented, with emphasis on differential diagnosis and the process for confirmation of the diagnosis. The treatment consists of discontinuing the use of cinnamon products. Clinicians will be able to recognize this disorder following a careful clinical examination and detailed history. This recognition is important in order to avoid invasive and expensive diagnostic procedures.
\end{abstract}

Keywords: Cinnamon-contact stomatitis, contact stomatitis, differential diagnosis, hypersensitivity, oral mucosa lesion.

\section{INTRODUCTION}

Contact stomatitis is a well-established condition that can be caused by a wide variety of agents, including cinnamaldehyde or cinnamon essential oil, which are commonly used as flavoring agents in foods, beverages, candies and hygiene products [1, 2]. Most of people consume cinnamoncontaining products regularly; however, a few cases on cinnamon-induced oral mucosal contact reaction have been reported. In this respect, a recent review of the literature has retrieved only 12 publications on cinnamon contact stomatitis over the last three decades [3]. In the most of the reported cases the oral mucosal lesions were associated with the use of toothpaste and chewing gum containing cinnamon [3].

Signs and symptoms of contact allergic reaction affecting the oral mucosa may mimic other common oral disorders, which along with the lacking of specific histopathologic findings associated with this condition makes its diagnosis quite difficult. Patients usually seek many consultations before a proper diagnosis is made [3-5].

The present article reports a case of oral mucosa reactions to cinnamon-flavored mints; emphasis is given on the process for disclosing the contact agent and on the differential diagnosis.

\section{CASE REPORT, DIFFERENTIAL DIAGNOSIS AND MANAGEMENT}

A 64-year-old white woman was referred to our clinic for evaluation of symptomatic oral lesions that had been present for 3 days. The patient was complaining of a constant

\footnotetext{
*Address correspondence to this author at the Universidade de São Paulo, Faculdade de Odontologia, Departamento de Estomatologia, Disciplina de Estomatologia Clínica, Av. Prof. Lineu Prestes, 2227, Cidade Universitária, São Paulo, 05508-000, SP - Brazil; Tel/Fax: +55-11-38641372;

E-mail: damiglia@usp.br
}

burning sensation along with roughness and thickness on the oral mucosa. The intraoral examination revealed a detachable white-yellowish plaque on the hard palate and an erythematous patch partially covered by a thin, yellowish, fibrinous plaque on the left buccal mucosa (Figs. 1a and 1b). Her medical history revealed an ongoing 3-year treatment with antidepressive drugs. She reported being a one-pack a day smoker for 45 years.

Differential diagnosis included mucous membrane pemphigoid, lichenoid contact reaction, erythema multiform and contact stomatitis. The first one was excluded since the onset of the lesions of the present case was abrupt, which is not the usual pattern of the development of oral lesion in mucous membrane pemphigoid. Lichenoid contact reaction was also considered but ruled out later on because the palatal mucosa (where lesions were also present) are never in contact with dental surfaces. Additionally, the patient had no amalgam filling on her upper-teeth. Erythema multiform and nonspecific contact stomatitis were very much possible, prompting additional investigation concerning any recent changes in the patient's habits. Hence, she reported no particular changes in her habits, except that she had switched the flavor of her mints (brand, Tic-Tac - manufactured in Ireland) ${ }^{*}$ to cinnamon shortly before the appearance of the lesions and considered it a possible cause. The patient was then advised to discontinue the use of cinnamon mints, which she did, obtaining great relief of symptoms, with complete healing of the lesions after 3 weeks (Figs. 1c and 1d).

In order to confirm the hypersensitivity contact reaction, it was suggested (with the patient's consent) that she go back to using the mints, what she did, and after a week the lesions recurred, (Figs. 2a and 2b). Reinterruption of the use of mints resulted once again in resolution of the lesions (Figs.

\footnotetext{
"Tic-Tac ingredients: sugar, maltodextrin, tartaric acid, natural and artificial flavors, rice starch, gum arabic, filling agent (magnesium stearate), artificial colors, glazing agent (carnauba wax).
} 
2c and 2d). Based on the clear relationship of the lesions and cinnamon flavoring, the diagnosis was contact stomatitis reaction.
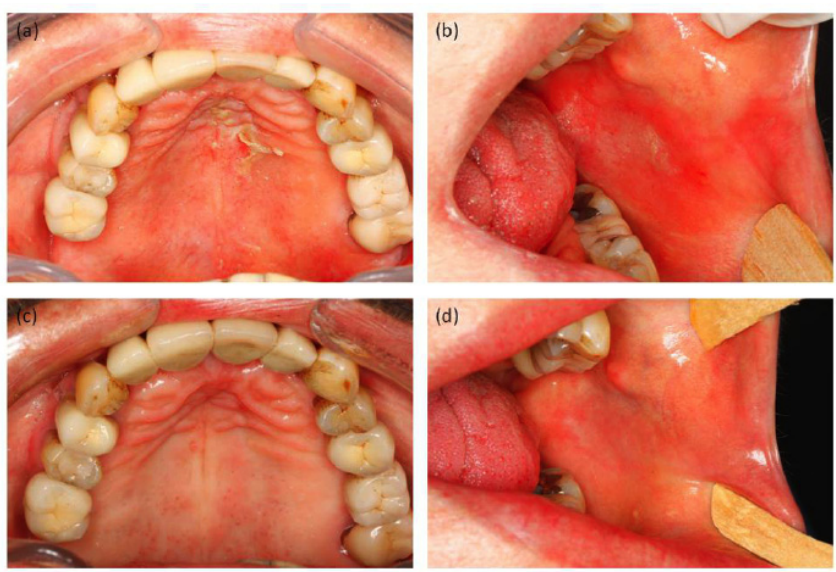

Fig. (1). (a): Detachable white-yellowish plaque with a slightly erythematous mucosa beneath it, located on the palate. (b): An erythematous patch with a yellowish thin plaque on the left buccal mucosa. (c) and (d): Complete remission of the lesions after discontinuance of the cinnamon mints.
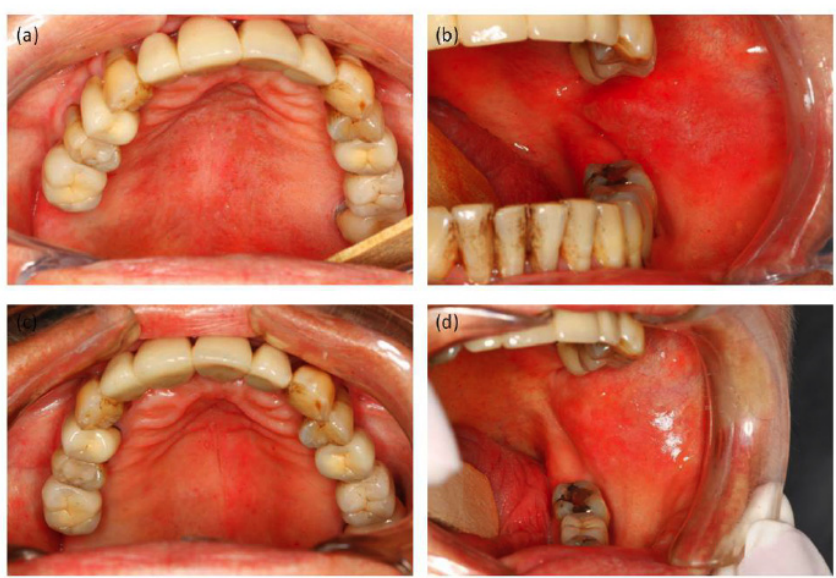

Fig. (2). (a) and (b): Recurrence of the lesions on the palate, but more evident on the buccal mucosa after the patient had been rechallenged with cinnamon mints. (c) and (d): Disappearance of the lesions following reinterrruption of the use of mints.

\section{DISCUSSION}

Cinnamon-induced contact stomatitis is a relatively uncommon reaction [2]. The majority of cases are associated with the consumption of products containing cinnamaldehyde, cinnamic acid or cinnamon essential oil, which are used as flavoring agents in oral hygiene products, foods, chewing gums and other products $[4,5]$. Clinical presentation of oral lesions is heterogeneous and can include pain and burning sensation, with urticarial swelling, erythematous patches, ulceration, adherent and peeling white patches, sloughing and vesicular lesions $[1,4,6]$. Besides being underestimated by clinicians, the nonspecific signs and symptoms of contact stomatitis pose difficulty for the diagnosis $[3,4]$. In this context, a careful clinical history is crucial for a prompt diagnosis.
Calapai et al. (2014), based on their critical review of cases reported in the literature, proposed an algorithm for diagnosis and clinical management of cinnamon contact stomatitis. In it, the authors emphasized that the process to disclose a contact stomatitis reaction should be based mainly on an accurate examination of the oral cavity coupled with a careful history of the initial development of the lesion(s). The diagnosis confirmation lies on the withdrawal of the suspected compound with the disappearance of lesions, followed by a recurrence of lesions after the reintroduction (with the patient's consent) of the same agent. Yet, the authors suggest the patch test in order to confirm the allergy. Nevertheless, they point some difficulties of this test, such as the analysis of the positive result and the requirement of a multidisciplinary team, besides the risk of false negative results. Invasive and expensive investigations were recommended only in the persistent cases.

The management of the present case was carried out in accordance with the diagnosis process outlined in the aforementioned study [3]; the first step was the withdrawal of the cinnamon mints, leading to the complete healing of the lesions. This was followed by the recurrence of lesions when the patient was rechallenged with the mints. This procedure was sufficient to confirm the diagnosis of cinnamon contact stomatitis. Additionally, the patient has been free of any oral lesion ever since she stopped using any cinnamon-containing products.

Allergic contact stomatitis is a hypersensitivity reaction (type IV) that affects only individuals who have previously been sensitized to the allergen $[1,6]$. Due to the cascade of cellular events involved, contact stomatitis does not become evident until several hours or even days after exposure to the antigen; hence termed as "delayed hypersensitivity reaction".

Lesions typically develop at sites of direct exposure to cinnamon agents [7]. Hence, oral anatomic distribution may be generalized when associated with liquid or pasty products, or more focal when solid products are used. The histopathologic aspect of allergic contact stomatitis is nonspecific but generally consistent with the clinical diagnosis $[1,8]$. Treatment consists of eliminating the causal agent and instructing the patient to avoid using products containing cinnamon.

\section{CONCLUSION}

Cinnamon contact stomatitis may present as non-specific clinical features, causing misdiagnosis. Careful anamnesis is essential to establish the prompt diagnosis and provide suitable clinical management. Complex procedures in the process of diagnosis may be unnecessary. Clinicians should suspect of this condition whenever patients report use of cinnamon products.

\section{CONFLICT OF INTEREST}

The authors confirm that this article content has no conflict of interest.

\section{ACKNOWLEDGEMENTS}

We would like to thank Professors Celso Lemos and Fabio Alves for their important contribution for the diagnosis process of the present case. 


\section{REFERENCES}

[1] Tremblay S, Avon SL. Contact allergy to cinnamon: case report. J Can Dent Assoc 2008; 74: 445-61.

[2] Bousquet PJ, Guillot B, Guilhou JJ, Raison-Peyron N. A stomatitis due to artificial cinnamon-flavored chewing gum. Arch Dermatol 2005; 41: 1466-7.

[3] Calapai G, Miroddi M, Mannucci C, Minciullo PL, Gangemi S. Oral adverse reactions due to cinnamon-flavoured chewing gums consumption. Oral Dis 2014; 20: 637-43.

[4] De Rossi SS, Greenberg MS. Intraoral contact allergy: a literature review and case reports. JADA 1998; 129: 1435-41.
[5] Nadiminti H, Alison Ehrlich A, Udey MC. Oral erosions as a manifestation of contact sensitivity to cinnamon mints. Contact Dermat 2005; 52: 46-7.

[6] Allen CM, Blozis GG. Oral mucosal reactions to cinnamonflavored chewing gum. J Am Dent Assoc 1988; 116: 664-7.

[7] Siqueira AS, Santos CC, Cristino MR, Silva DC, Pinheiro Md, Pinheiro JJ. Intraoral contact mucositis induced by cinnamonflavored chewing gum: A case report. Quintessence Int 2009; 40: 719-21.

[8] Miller RL, Gould AR, Bernstein ML. Cinnamon-induced stomatitis venenata, Clinical and characteristic histopathologic features. Oral Surg Oral Med Oral Pathol 1992; 73: 708-16.

(C) Vivas and Migliari; Licensee Bentham Open.

This is an open access article licensed under the terms of the Creative Commons Attribution Non-Commercial License (http://creativecommons.org/licenses/by-nc/3.0/) which permits unrestricted, non-commercial use, distribution and reproduction in any medium, provided the work is properly cited. 